\title{
INFLUENCE OF SPECIES COMPOSITION OF BIOCORRIDORS ON THE ABUNDANCE OF APHIDS IN CEREAL FIELDS
}

\author{
OLGA M. C. C. AMEIXA ${ }^{1,3, *}$, RADKA DVOŘÁKOVÁ2, JAN ŠIPOŠ ${ }^{3,4}$, \\ and PAVEL KINDLMANN 3,5
}

\author{
${ }^{1}$ Department of Biology and CESAM, University of Aveiro, Aveiro, Portugal \\ 2 University of South Bohemia, České Budějovice, Czech Republic \\ ${ }^{3}$ Department of Biodiversity Research, Global Change Research Centre AS CR, Na sádkách 7, 37005 České Budějovice, Czech Republic \\ ${ }^{4}$ Faculty of Science, University of Ostrava, 71000 Ostrava, Czech Republic \\ ${ }^{5}$ Institute for Environmental Studies, Charles University, Benátská 2, Prague, Czech Republic \\ *Corresponding author: olga.ameixa@ua.pt
}

\begin{abstract}
Agriculture intensification in most European countries over the last 50 years resulted in a significant loss of biodiversity in agro-ecosystems. Attempts are now being made to restore originally complex agricultural landscapes by splitting large fields into smaller units using biocorridors, which are linear elements consisting of trees and shrubs. Such non-crop habitats can act as refuges both for insect predators that may potentially act as biocontrol agents and for insect pests. Bird cherry, Prunus padus (L.), is a winter host of a cereal pest and vector of cereal virus, the aphid Rhopalosiphum padi (L.), and is commonly planted in these biocorridors. The question arises, whether and to what extent the presence and distribution of $P$. padus in biocorridors influences the abundance of $R$. padi in nearby fields. This was addressed by monitoring spatial and temporal population dynamics of $R$. padi in two fields each adjacent to the newly established biocorridor but adjacent to parts of the corridor with different species compositions (only one with P. padus). Our results showed that this aphid colonized the field adjacent to that part of the corridor with P. padus but not the other field. In the second field colonization started close to one edge distant from the corridor and with no P. padus in the vicinity. After excluding the variability explained by spatial and temporal factors we also tested for the effect of environmental factors (weather conditions) on the remaining variability. Of the environmental factors tested, humidity accounted for most of the variability.
\end{abstract}

Keywords: biocorridors, Prunus padus, Rhopalosiphum padi, pest refuge, spatial distribution

\section{Introduction}

Simplification of the structure of the landscape (removal of hedges between fields, increase in average field size and simultaneous decline in the number of fields), due to intensification of farming in most European countries over the last 50 years, has contributed to a significant reduction in the biodiversity recorded in farmland in Europe (Siriwardena et al. 2000; Robinson and Sutherland 2002; Benton et al. 2003). Plants, insects, and especially birds have declined in numbers in European agroecosystems in recent years (Pain and Dixon 1997; Chamberlain et al. 2000; Söderström and Pärt 2000). Currently there are attempts to restore the complex agricultural landscape that previously existed by splitting large fields into smaller units by means of biocorridors, which are linear elements consisting of trees and shrubs. Such non-crop habitats can act as refugia for plants, insects, birds and mammals (Johnson and and Beck 1988; Hinsley and Bellamy 2000; Perfecto and Vandermeer 2002; Duelli and Obrist 2003; Van Buskirk and Willi 2004), among which are natural enemies, which can potentially improve natural pest control in adjacent fields (Ives et al. 2000; Wilby and Thomas 2002). In addition, biocorridors can also facilitate movement of species between patches of habitat (Burel and Baudry 1990; Joenie et al. 1997). However, such non-crop habitats may also act as reservoirs of pests, which colonize crops (van Emden 1965).
Due to the changes in the political system after 1989, the Czech Republic is an ideal country for testing the effects of corridors in agroecosystems. Prior to 1948, each of the tens of thousands of small farms consisted of dozens of small fields. After 1948, agriculture in the country was collectivized, hedges removed and extremely large fields created in the belief that they could be cultivated more economically. After 1989, land was returned to its original owners, which created the situation that most of the existing large fields had now lots of owners; some of the new owners rented these fields to the newly restructured cooperative farms, but other owners decided to farm their land. This resulted in a complex reform of the land in the Czech Republic, which resulted in a reshuffling the possessions according to the new situation. The aim was to make cultivation more feasible by offering each owner an equally-sized, but less fragmented piece of land. During this reform, many fields were split by creating biocorridors, in order to improve landscape structure and restore lost biodiversity; the cost of this was paid by the state. These biocorridors can now be used as a natural laboratory for studying the effects of biocorridors on biodiversity.

One of the commonest plants in these biocorridors is Prunus padus L. (bird cherry), which is also the winter host of the cereal aphid, Rhopalosiphum padi (L.). At the beginning of summer, this aphid leaves P. padus and moves to Gramineae, mainly cereals (Blackman and Eas- 
top 2000). The large area under cereals in the contemporary agricultural landscape enabled $R$. padi to become very abundant (Kindlmann and Dixon 1990). R. padi is a serious pest of cereals, because it negatively affects them not only by sucking phloem sap, but also because it transmits cereal virus diseases, like barley yellow dwarf virus, BYDV (Dedryver and Harrington 2004).

The question now arises, whether and to what extent the presence of Prunus padus in biocorridors affects the abundance of $R$. padi in adjacent fields. This was addressed by monitoring the spatial and temporal changes in abundance of $R$. padi in two fields adjacent to a recently established biocorridors. We attempt to answer the following questions: What effect does. P. padus in bocorridors have on the colonization of fields by $R$. padi? Does the abundance of $R$. padi decrease or increase from the edge to the center of a field?

\section{Methods}

\section{Study Site}

This study was conducted in South Bohemia, between Sedlec and Hlavatce $\left(49^{\circ} 4^{\prime} 14.63^{\prime \prime} \mathrm{N}, 14^{\circ} 16^{\prime} 24.39^{\prime \prime} \mathrm{E}-\right.$ Fig. 1). By planting a linear biocorridor with total area of $5079 \mathrm{~m}^{2}$ in 2000 , an originally large agricultural field was divided into two smaller fields, 23.5 and 11.7 ha in size. These two fields are bordered by two ponds in the north, by a road in the south and by an old fragmented natural corridor and a meadow in the west (Fig. 1). These fields are part of an agricultural mosaic, which includes two villages. The biocorridor consists mainly of Salix sp., Prunus spinosa and wild rose bushes (Rosa spp.). The Prunus padus trees are mainly located inside the corridor, bordered by willow trees (Salix sp.), and about 20 trees are located in one of the margins of the corridor adjacent to field 1 . Wheat was grown in the two adjacent fields in 2009 and 2010.
Meteorological data was obtained from the hydro-meteorology institute in České Budějovice, Czech Republic (which is located about $20 \mathrm{~km}$ from the study area). For the analyses we took daily means of these environmental variables: a) temperature; b) wind gust; c) humidity; d) air pressure; and e) wind direction.

\section{Experimental Design}

The monitoring of the aphid population started in 2010, first on the Prunus padus trees (in the margin near field 1), in order to obtain an accurate estimate of the time of the migration to cereals. The numbers of R. padi on 40 leaves per tree of 10 trees were counted on April 29, May 6, May 13 and May 25. In the fields, the number of $R$. padi on 20 tillers was counted at 5 positions along transects, which were perpendicular to the biocorridor and approximately $100 \mathrm{~m}$ apart from each other. In the larger of the two fields (field 1), there were 4 transects (each $\sim 400 \mathrm{~m}$ in length) and the number of aphids was counted on the tillers at 5 locations approximately $100 \mathrm{~m}$ along each transect. In the smaller field (field 2), there were 5 transects (each $\sim 300 \mathrm{~m}$ in length) and the number of aphids was counted on the tillers at 4 locations approximately $100 \mathrm{~m}$ apart along each transect (Fig. 1). Five counts were made during the season from late May until the beginning of July (May 25, June 2, June 15, June 25 and July 6).

\section{Statistical Analysis}

The relation between the presence of $P$. padus trees and infestation of wheat by $R$. padi was analyzed by comparing the abundance of aphids in the two fields, using a $t$-test.

The estimates of aphid abundance were compared among treatments for each distance from the corridor $(75$, $150,225,300,375 \mathrm{~m}$ ) in each field using a repeated-mea-

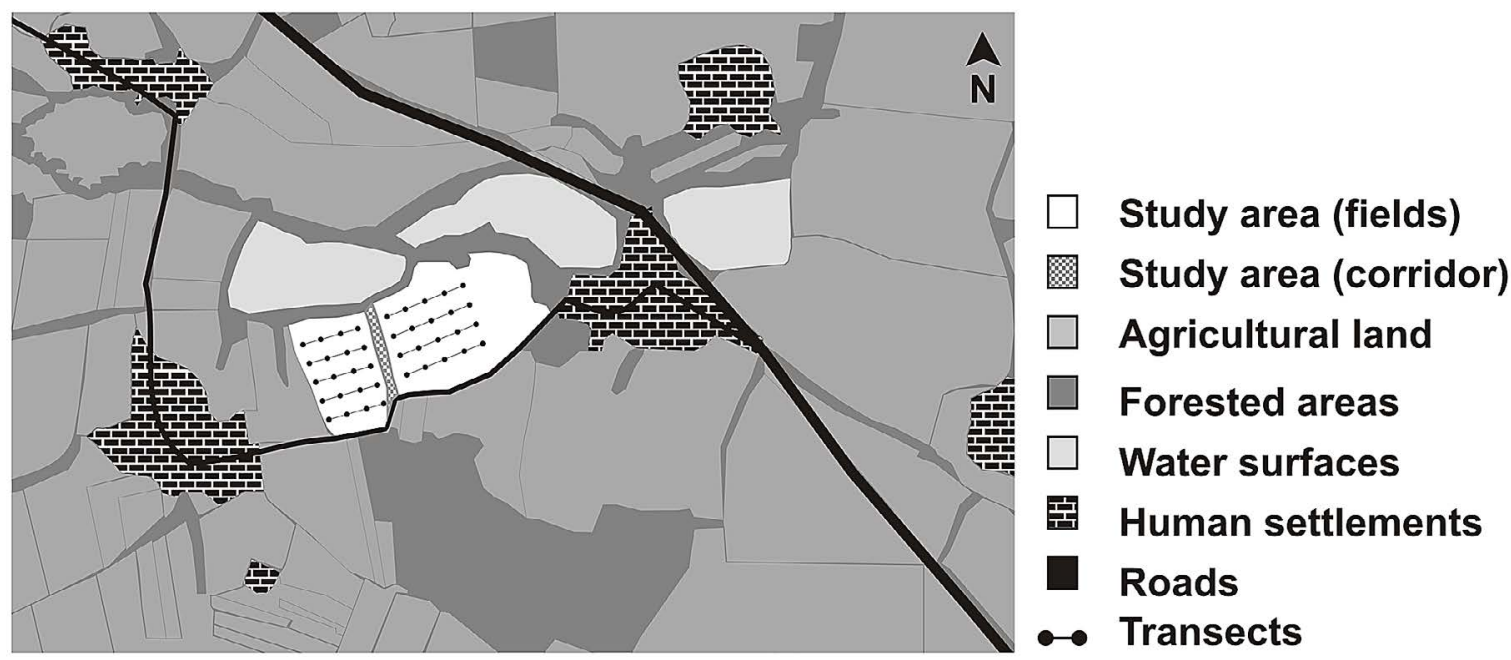

Fig. 1 Map of the area in which this study was carried out showing the corridor, the two fields and transects (lines) with sites sampled (dots) and surrounding landscape. 


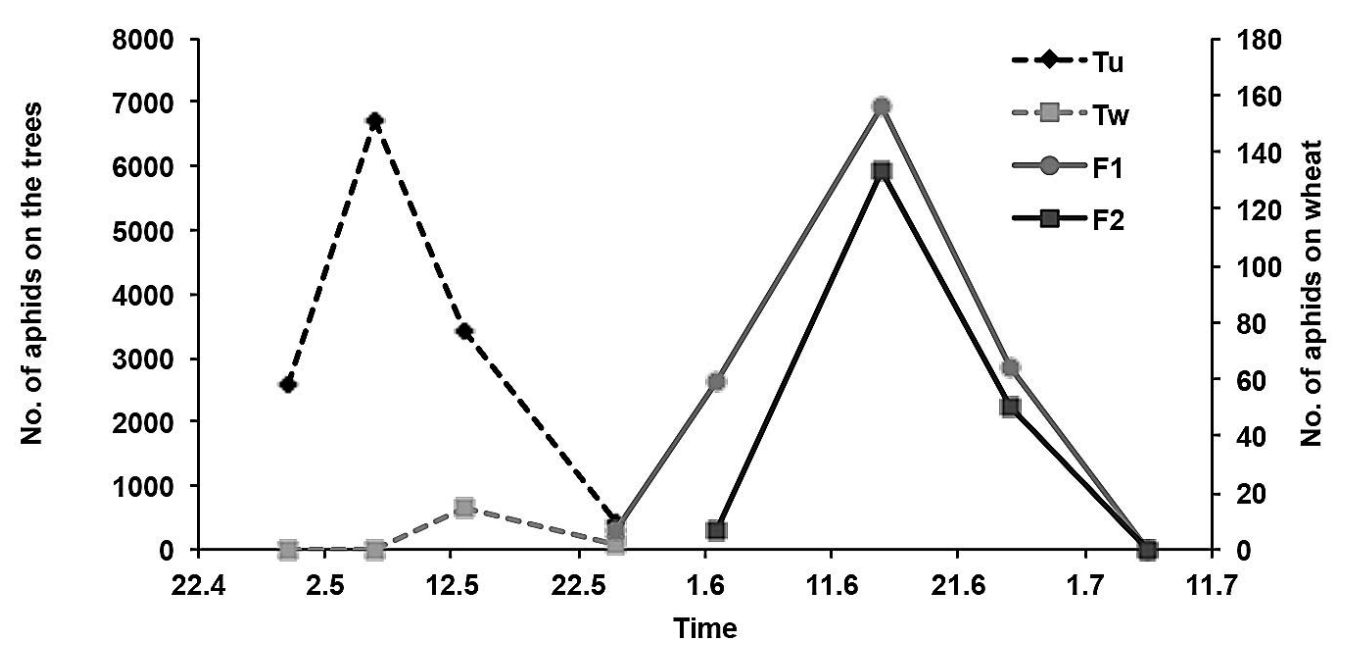

Fig. 2 Changes over time in the numbers of aphids recorded on Prunus padus in the corridor and the two fields sampled (Tu - total number of unwinged aphids on trees; Tw - total number of winged aphids on trees; F1 - field 1; F2 - field 2).

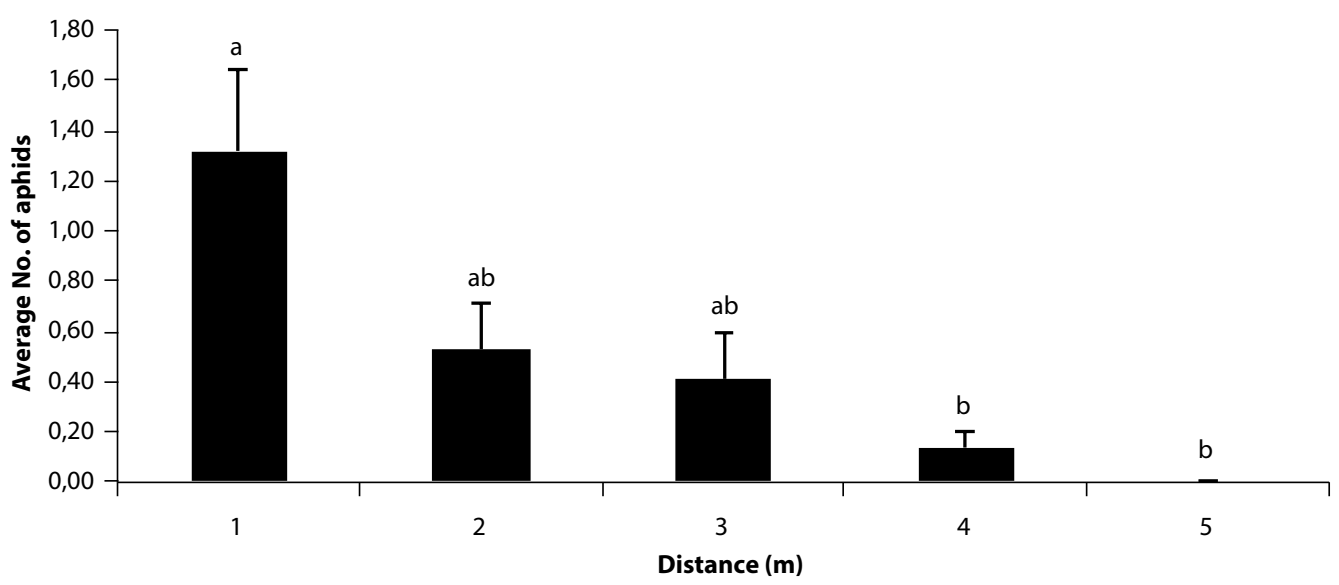

Fig. 3 Average number of aphids recorded at different distances in field 1 (+SE). Different letters represent significant differences between averages (Bonferroni pairwise comparisons).

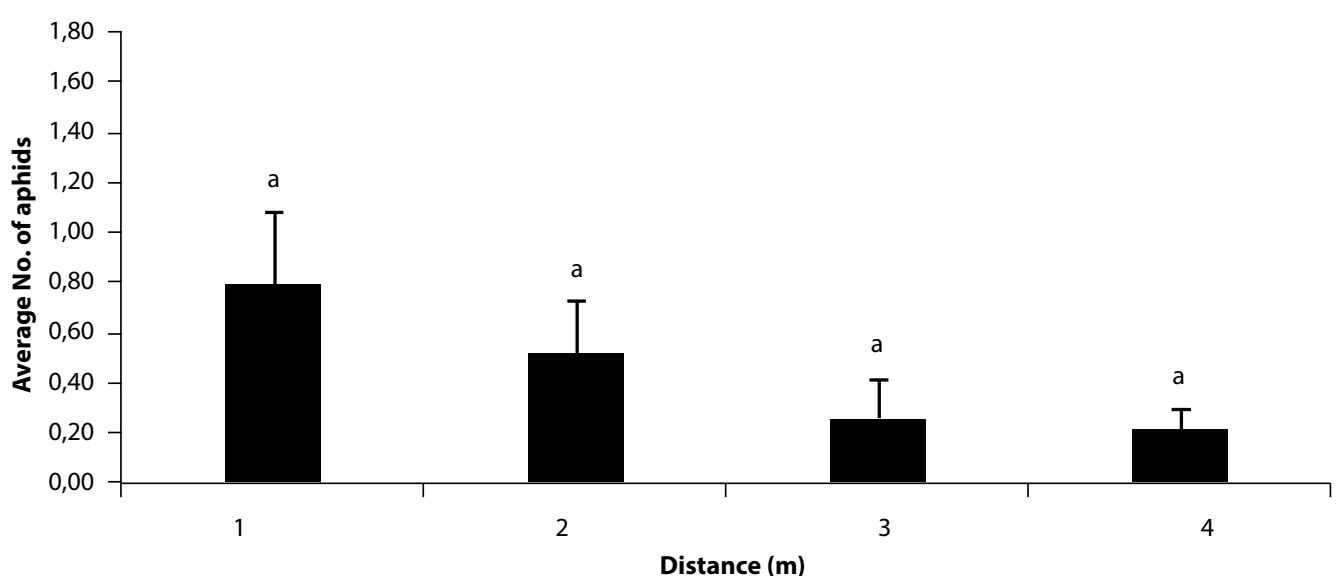

Fig. 4 Average number of aphids recorded at different distances in field 2 (+SE). Different letters represent significant differences between averages (Bonferroni pairwise comparisons). 
sures ANOVA's and applying the Greenhouse-Geisser (G-G) adjustment for tests of within-subject effects when the sphericity assumption was not met. These analyses were followed by pairwise comparisons among treatments using the Bonferroni-adjusted level of significance. The data was always $\log$ transformed $(\mathrm{y}=\ln (\mathrm{x}+1))$ prior to analyses to meet statistical assumptions.

The relationship between distance and time of colonization was modelled by general linear models (GLM) with a Poisson error distribution. Standard errors were corrected using a Quasi-Poisson model to compensate for over-dispersion. In the final model we used abundance of aphids as the response variable and the date of counting and distance from the corridor as explanatory variables. The distance and date were modelled as cubic regression spline.

To test the effect of weather conditions on the dispersion of $R$. padi we used a step wise selection procedure in order to obtain the most parsimonious combination of factors that accounted for the highest variability in aphid dispersion. To fit the weather conditions on aphid abundance we used generalized additive mixed models (GAMM) with field as a random variable. The environmental variables were smoothed by cubic regression spline. Degree of smoothness for GAMM model terms was estimated using the generalized cross validation criterion.

We used an F-test to determine if weather conditions significantly accounted for the remaining variability in aphid dispersion after removing the variability accounted for by distance and date. These two factors were added first since we used them as covariables.

\section{Results}

Fig. 2 shows the numbers of aphids recorded on the trees and in the two wheat fields. The aphids appeared on the trees in late April, peaked in abundance the following week, after which the number of winged aphids increased and they started to migrate. These aphids were first recorded on the cereal plants at the end of May, first in field 1 and then in field 2. The peak number of aphids in both fields was recorded in the middle of June.

The results of the ANOVA with repeated measures with a G-G correction for field 1 (Fig. 3), revealed that the mean scores for the distances were statistically significantly different $\left(\mathrm{F}_{(2.069)}=7.785, \mathrm{P}<1.17 \mathrm{E}^{-0.7}\right)$. The results of the Bonferroni post-hoc test, revealed that the number of aphids recorded close $(75 \mathrm{~m})$ to the corridor differed significantly from the numbers recorded at 300 and $375 \mathrm{~m}$ from the corridor

The results of the ANOVA with repeated measures with a G-G correction for field 2 (Fig. 4), did not revealed any significant differences between the aphid counts recorded at the four distances into the field $\left(\mathrm{F}_{(1.92)}=3.013\right.$, $\mathrm{P}<0.063)$.

Distance from the corridor, date and their interactions significantly explained the variability in aphid distribution (Table 1). Also, the significant interaction showed that the abundance of aphids had different progressions in time at different distances. The interaction between field and distance was nearly significant and it indicates that the abundance of aphids had a different progression through space in both fields. The interaction between the distance from the corridor and date

Table 1 Quasi-Poisson generalized linear model fitted to the aphid abundance recorded in both fields at different distances and on different dates "bs" represents cubic regression spline. Field was treated as a random variable.

\begin{tabular}{|l|c|c|c|c|c|c|}
\hline & Df & Deviance & Resid. Df & Resid. Dev & Pr (>F) \\
\hline NULL & & & 179 & 144.914 & 144.718 & 0.388 \\
\hline Field & 1 & 0.196 & 178 & 122.057 & 14.952 & 13.356 \\
\hline bs(distance) & 3 & 22.660 & 175 & 172 & 84.724 & $<0.001$ \\
\hline bs(date) & 3 & 20.242 & 163.091 & 80.831 & $<0.001$ \\
\hline bs(distance):bs(date) & 9 & 3.894 & 160 & & 2.569 \\
\hline field:bs(distance) & 3 & & & & 0.056 \\
\hline
\end{tabular}

Table 2 Quasi-Poisson generalized additive mixed model fitted to aphid abundance recorded in both fields at different distances, dates and humidities. "bs" represents cubic regression spline. Field was treated as a random variable.

\begin{tabular}{|l|c|c|c|c|c|c|}
\hline & Df & Deviance & Resid. Df & Resid. Dev & F & Pr (>F) \\
\hline NULL & & & 179 & 232.26 & & \\
\hline bs(distance) & 3 & 56.460 & 176 & 175.80 & 26.035 & $<0.001$ \\
\hline bs(date) & 3 & 49.591 & 173 & 126.21 & 22.868 & $<0.001$ \\
\hline bs(humidity) & 2 & 2.057 & 172 & 124.15 & 4.845 & 0.043 \\
\hline
\end{tabular}

European Journal of Environmental Sciences, Vol. 4, No. 1 


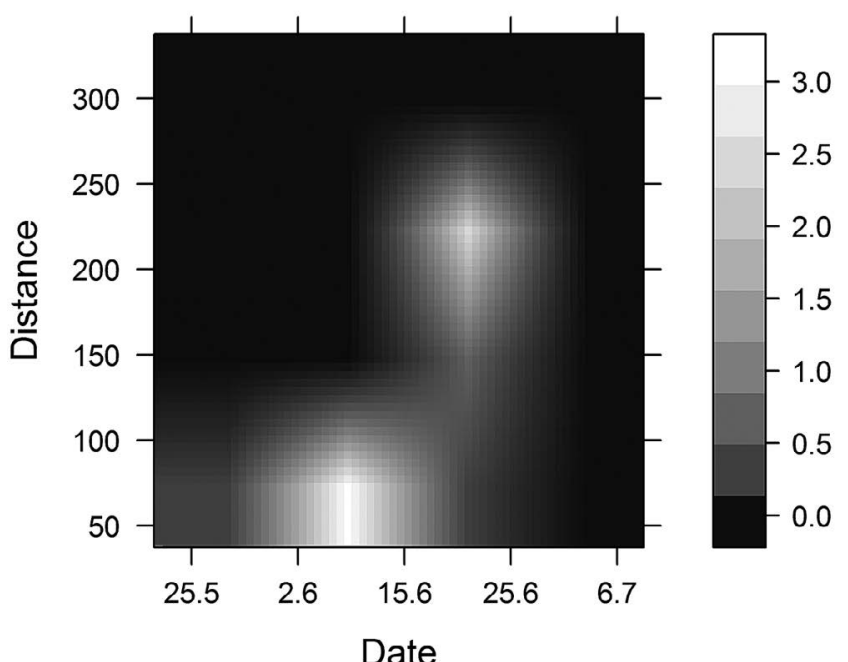

Fig. 5 Contour plot of the predicted values of the GLM model for field 1 using aphid abundance as the response variable and distance from corridor and date as explanatory variables. (Intensity of blackness indicates the average number of aphids.)

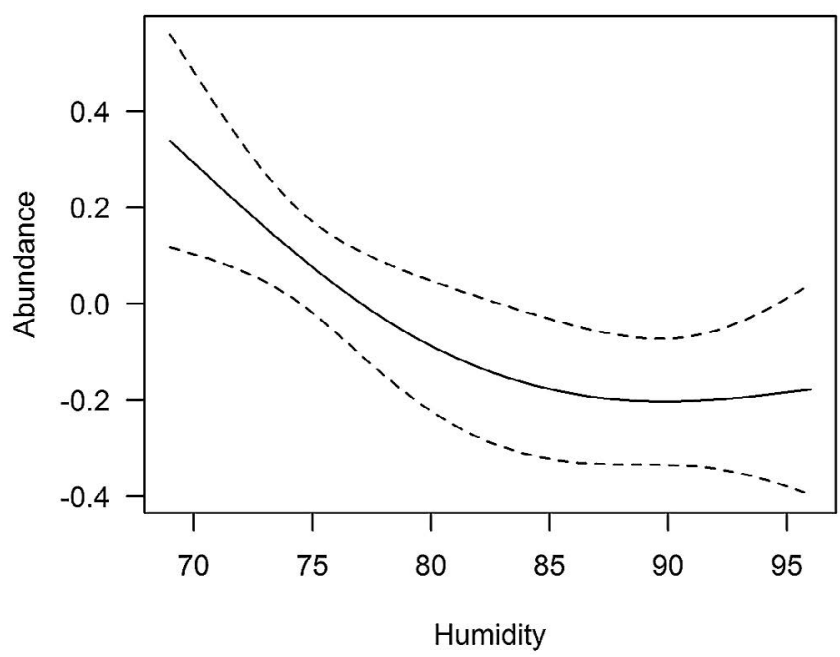

Fig. 7 Partial residual plot of the values predicted by a generalized additive model of the effect of date, distance from the corridor and humidity on aphid abundance. Dashed line represents standard-error Partial residuals are residuals that remain after fitting all factors except the factor of interest.

accounted for $30 \%$ of the variability in the distribution of the aphid.

When we removed the variability in the distribution of the aphid explained by spatial and temporal factors (distance from corridor and date) the $14 \%$ of variability remaining was explained by humidity (Table 2 ). $\mathrm{Hu}$ midity was chosen by a step-wise procedure as the most significant of the weather factors recorded (temperature, precipitation, air pressure, wind gust, wind direction). The negative correlation between aphid density and humidity was fitted using the GAMM model (Fig. 7).

Aphid distribution in field 1 was significantly dependent on the interaction between date and distance from

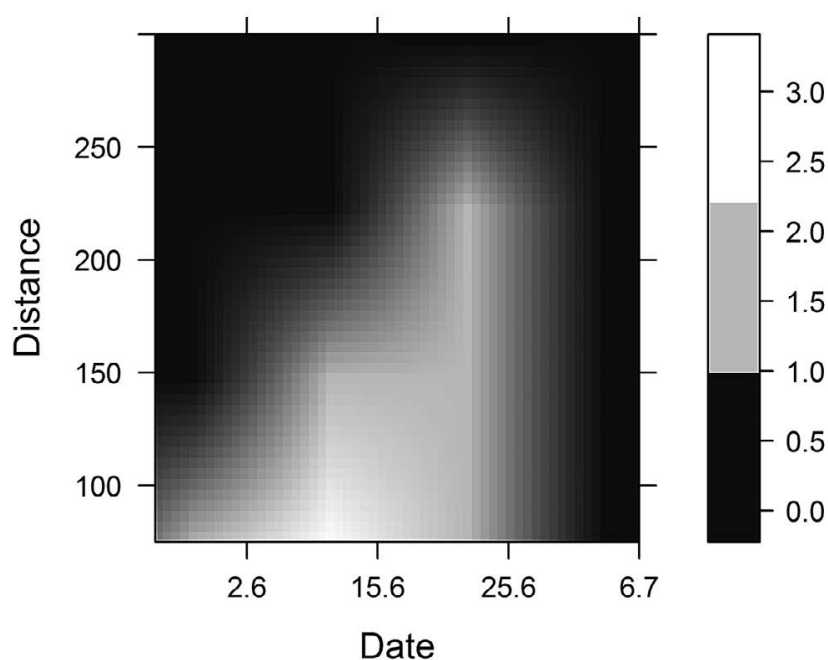

Fig. 6 Contour plot of the predicted values of the GLM model for field 2 using aphid abundance as the response variable and distance from corridor and date as explanatory variables. (Intensity of blackness indicates the average number of aphids.)

the corridor $\left(\mathrm{F}_{(4,95)}=75.49, \mathrm{P}=0.004\right)$. The GLM model for field 1 predicts how aphid abundance differs in time and space, and the colonization of field 1 started in the vicinity of the corridor and gradually spread through the field (Fig. 5). On the other hand, the interaction between date and distance from the corridor was non-significant in field $2\left(\mathrm{~F}_{(4,75)}=0.96, \mathrm{P}=0.43\right)$. Comparing figures 5 and 6 it is clear that the progression in time in aphid abundance in both fields was similar but that the GLM model predicts a greater abundance of aphids in field 1 .

\section{Discussion}

It is often stressed that non-crop habitats can act as refuges for natural enemies, but the fact that they may also be refuges for pests is usually ignored. Unlike Östman et al. (2001), who did not find any indication that $R$. padi colonized cereal crops from non-crop habitats, the results of this study indicate that biocorridors containing $P$. padus can serve as a winter refuge for the pest species, R. padi, and facilitate its colonization of cereal fields, when they are in the immediate vicinity of cereals. However, if $P$. padus is surrounded by other trees, these seem to act as barriers to aphid dispersion. As field 2 was colonized by $R$. padi it is likely the aphids came from another source since there are no $P$. padus growing around the margins of this field.

When P. padus is present in a biocorridor, the number of $R$. padi infesting cereals in adjacent fields is likely to be increased over a distance of up to several hundred meters. Thus, when planting biocorridors in an agricultural landscape, $P$. padus should be avoided as it is the winter host of the aphid pest, $R$. padi. Alternatively, if $P$. padus is planted, cereals should not be grown closer than about 
$300 \mathrm{~m}$ from such a biocorridor. The buffer zone between the biocorridor and cereal fields may be used either for cultivating crops that are not mature enough to be colonized by R. padi, when it leaves its winter host (e.g., maize), or are not hosts of $R$. padi (e.g., oil seed rape). The species of plants in biocorridors should be carefully chosen with respect to their potential effect on the surrounding fields however, potential negative effect can be prevented by not planting $P$. padus.

Weather conditions, such as temperature, rain or wind can have a marked effect on aphid numbers. We did not find any influence of these variables in our fields, but we found a negative correlation between aphid abundance and humidity. This finding is consistent with Leather (1985) in which apterous females of R. padi were significantly more fecund on oat seedlings growing in conditions of low relative humidity, which the author attributed to the increased transpiration of the plants under these conditions. In addition to this, we believe that the lack of management (pruning) of the corridor studied decreased the circulation of air around the trees, which remained wet for longer and it is well known that aphids are very susceptible to fungal diseases when it is humid.

\section{Acknowledgements}

The research was supported by the grants No. GEVOL /11/E036 of the GA CR and CZ.1.05/1.1.00/02.0073 (CzechGlobe) of the MSMT.

\section{REFERENCES}

Benton TG, Vickery JA, Wilson JD (2003) Farmland biodiversity: is habitat heterogeneity the key? Trends Ecol Evol 18: 182-188.

Blackman RL, Eastop VF (2000). Aphids on the world's crops. An identification and information guide. Wiley, New York.

Burel F, Baudry J (1990) Hedgerow network patterns and process in France. In: Zonneveld IS, Forman RTT (eds) Changing Landscapes: An Ecological Perspective, pp. 99-120. Springer, New York.

Chamberlain DE, Fuller RJ, Bunce RGH, Duckworth JC, Shrubb M (2000) Changes in the abundance of farmland birds in relation to the timing of agricultural intensification in England and Wales. J Appl Ecol 37: 771-788.
Dedryver C-A, Harrington R (2004) BYD epidemiology and forecasting. In: Lapierre H, Signoret P (eds) Viruses and Virus Diseases of Poaceae, pp. 155-170. Editions INRA, France.

Duelli P, Obrist MK (2003) Regional biodiversity in an agricultural landscape: the contribution of seminatural habitat islands. Basic Appl Ecol 4: 129-138.

Hinsley SA, Bellamy PE (2000) The influence of hedge structure, management and landscape context on the value of hedgerows to birds: A review. J Environ Manage 60: 33-49.

Ives AR, Klug JL, Gross K (2000) Stability and species richness in complex communities. Ecol Lett 3: 399-411.

Joenie W, Burel F, Gerowitt B, Paoletti MG, Thomas CFG, Moonem C, Baudry J, Le Coeur D, Kleijn D, Schippers P, Kopp A, Thenail C, Marshall EJP (1997) Field boundary habitat for wildlife, crop and environmental protection. Long Ashton Research Station, Bristol, UK.

Johnson RJ, Beck MM (1988) Influences of shelterbelts on wildlife management and biology. Agric Ecosystems Environ 22-23: 301-335.

Kindlmann P, Dixon AFG (1990) Role of plant abundance in determining the abundance of herbivorous insects. Oecologia 83: 281-283.

Leather SR (1985) Atmospheric humidity and aphid reproduction. Z Angew Entomol 100: 510-513.

Östman Ö, Ekbom B, Bengtsson J (2001) Landscape heterogeneity and farming practice influence biological control. Basic Appl Ecol 2: 365-371.

Pain D, Dixon J (1997) Why farming birds in Europe? In: Pain D, Pienkowski M (eds) Farming Birds in Europe, pp. 1-24. Academic Press, London.

Perfecto I, Vandermeer J (2002) Quality of Agroecological Matrix in a Tropical Montane Landscape: Ants in Coffee Plantations in Southern Mexico. Conserv Biol 16: 174-182.

Robinson RA, Sutherland WJ (2002) Post-war changes in arable farming and biodiversity in Great Britain. J Appl Ecol 39: $157-176$.

Siriwardena GM, Baillie SR, Crick HQP, Wilson JD (2000) The importance of variation in the breeding performance of seed-eating birds in determining their population trends on farmland. J Appl Ecol 37: 128-148.

Söderström B, Pärt T (2000) Influence of Landscape Scale on Farmland Birds Breeding in Semi-Natural Pastures. Conserv Biol 14: 522-533.

Van Buskirk J, Willi Y (2004) Enhancement of Farmland Biodiversity within Set-Aside Land. Conserv Biol 18: 987-994.

Van Emden HF (1965) The role of uncultivated land in the biology of crop pests and beneficial insects. Sci Hortic-England 17: $121-136$

Wilby A, Thomas MB (2002) Natural enemy diversity and pest control: patterns of pest emergence with agricultural intensification. Ecol Lett 5: 353-360. 